\title{
Exploration of the Redevelopment Strategy of Traditional Handicraft Industry under the Background of "Intangible Cultural Heritage" Protection
}

\author{
Xiaolin Jia \\ School of Design Art, Xijing University, Xi'an 710123, China \\ 503058868@qq.com
}

\begin{abstract}
At present, the state vigorously pursues various policies on the protection of "intangible cultural heritage" protection, which injects vitality into the re-development of traditional culture. Based on the research, starting from the perspective of craftsmanship and people's livelihood, the economic, cultural and social value of handicraft are re-recognized and explored. The present situation of some traditional handicraft industries is analyzed, and some innovative strategies to promote the inheritance and development of traditional handicraft are explored, trying to enlighten the reform and development of traditional handicraft. Starting from the summary of exploration experience and combing of exploration practice on traditional handicraft reproduction at home and abroad, the mode and organizational form of traditional handicraft reproduction is discussed. Moreover, the practical significance of traditional handicraft reproduction is analysed from three aspects: rural construction, livelihood economy and local culture. From the national yuan-field, the sustainable development of traditional handicraft reproduction is discussed from three aspects: government, school and people. Taking the wheat straw reproduction in Pucheng, Shaanxi Province as an example, the process of traditional handicraft reproduction and the possibility of its widespread implementation are expounded. It is pointed out that reproduction is the source of vitality and power for the modern transformation of traditional handicraft.
\end{abstract}

Keywords: traditional craft; handicraft industry; inheritance.

\section{Introduction}

At present, with the vigorous development of the national economy, great attention has been paid to the development of the "soft power" of the cultural industry. Especially in the aspect of national traditional culture, various policies have been put forward to protect the intangible cultural heritage. Many folk traditional handicraft skills have been listed in the "intangible cultural heritage protection" ranks. On the other hand, with the rapid economic growth and the improvement of people's living standards, people turn to have a higher level of demand for spiritual and cultural aspects, more and more people begin to pay attention to traditional handicraft, and this demand is also growing. However, many traditional handicraft industries, due to the various problems faced in the process of inheritance, especially the loss or lack of employees, have gradually declined, and many skills even trapped into a "dead art" situation because there is no inheritor [1].

In recent years, various parts of the country are visited and field investigations and interviews are conducted on some traditional handicraft industries, such as Naxi traditional embroidery in Yunnan Province, Shoushan stone carving in Fuzhou, Fujian Province, Dongyang wood carving in Zhejiang Province, Yueqing boxwood carving in Zhejiang Province, and wood carving in Wuhan, Hubei Province. Through in-depth investigation, the development status of these traditional handicraft industry is certainly understood, and its development prospect is worried about.

\section{Development of Traditional Handicraft Industry}

Although the state vigorously advocates the protection of intangible cultural heritage, promotes the re-development of the traditional craft industry, and puts many traditional handicraft and crafts into the ranks of "intangible cultural heritage protection", the traditional handicraft industry cannot be separated from the handicraft inheritance. Especially in those areas where the traditional craft 
production is very concentrated, the fact that the industry has been gradually decreasing occurs, which is mainly reflected in the following aspects:

\subsection{Long Cycle of Learning for the New Students in the Industry}

The cycle of the new apprenticeship is long and the training process is boring. Before the founding of the People's Republic of China, artists could endure the arduous academic process because of the difficulty of entering a certain industry and the lack of choice. However, in modern society, young people are impetuous and face many choices so that it is difficult for them to endure these boring training processes. Without firm beliefs, it is difficult to adhere to the process of learning. This is one of the universal factors for no inheritance that the traditional handicraft industry is facing. It is the same in some other traditional industries that have been well developed, such as jade carving, ivory carving, and Han embroidery [2].

\subsection{More Processes of the Traditional Handicraft Production}

Different from industrialized production, each piece of handicraft in the handicraft industry should be completed by the handicraftsman in accordance with different processes. As a traditional handicraft handed down for many years, some production processes have become part of the traditional cultural heritage, which is the added value of handicraft that can only be adjusted appropriately, but cannot be omitted. However, due to the large number of production processes and long time, many young people lack patience to learn these traditional crafts, which has become a bottleneck for the traditional crafts to inherit and develop in modern society [3].

\subsection{Unequal Level of Individual Qualifications of Practitioners}

Some of the more prosperous areas of traditional handicrafts are mainly concentrated in economically backward rural areas. Artists' skills are handed down from generation to generation, mostly for life, and many people do not go to school or the level of education is not high, qualifications are unequal and the educational level is low. If the qualifications are general, they can only copy the existing styles and are not good at designing new styles, which is not conducive to meeting the needs of social aesthetic development. Additionally, though there are some people highly qualified, they are difficult to break through themselves in aesthetic development because they do not receive timely understanding of the aesthetic needs of modern society and do not receive some professional aesthetic training [4].

\section{Innovative Ideas on the Inheritance and Development of Traditional Handicrafts}

Since modern times, agricultural production has been greatly affected by the impact of industrialization. At the same time, the change of people's lifestyle and the shrinkage of cultural space have a certain impact on the development of wheat straw technology, so that it gradually disappeared in people's lives. However, as a traditional handicraft lasting for thousands of years, wheat straw technology has not disappeared from life, but hidden in modern society. Once the opportunity is grasped and activated, it can still play its economic, cultural and social value. Nowadays, there are individuals, enterprises or companies mainly engaged in wheat straw production all over the country, and the reproduction of Pucheng wheat straw technology is of typical significance [5]. 


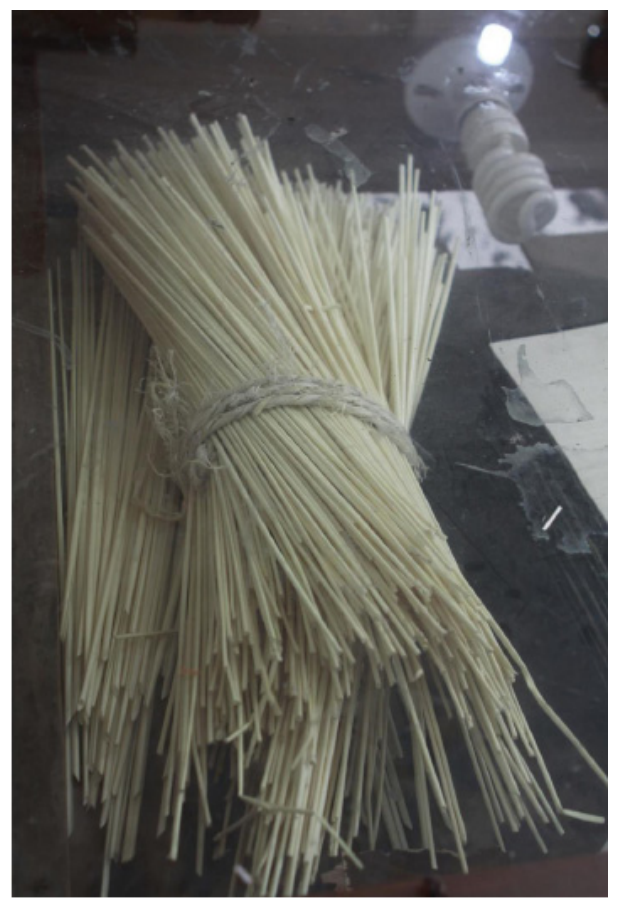

Figure. 1 Raw material for wheat straw technology

\subsection{Reproduction Process of Wheat Straw Technology in Pucheng}

In the 1980s, wheat straw technology generally pasted wheat straw on the drawing board or wood board after simple treatment, and the content of the picture was mostly text content, and finally added glass. Due to the limitation of materials, most of the wheat straw handicrafts in this period were bulky, inconvenient to carry and easy to break, and did not have a wide range of applicability or decoration.

In the early $1990 \mathrm{~s}$, due to the emergence of three-dimensional ironing technology, the form and content of wheat straw craft have been greatly improved, the original text-based form gradually evolved into a more aesthetic and artistic value of wheat straw crafts. At the same time, due to the renewal of materials, many light materials appear, such as resin glass, which overcomes the glass fragile shortcomings. Due to weight reduction, in the painting area, dust removal has greatly improved compared with the first generation [6].

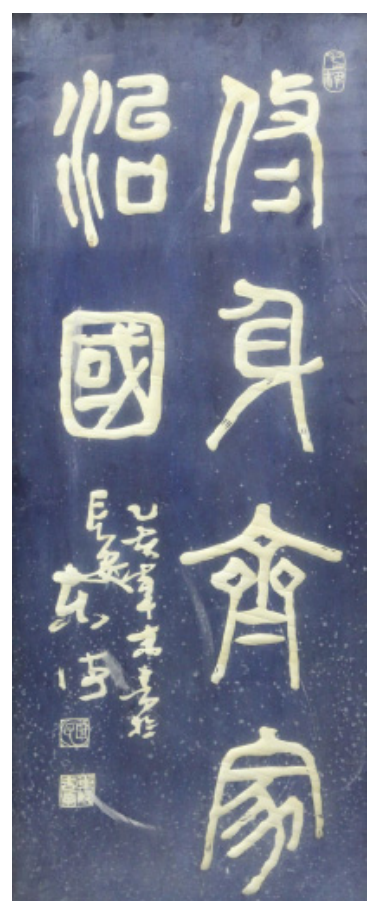

Figure. 2 Early wheat straw handicraft 
Since the beginning of the 20th century, with the further improvement of three-dimensional ironing technology, traditional folk themes and modern painting techniques are skilfully integrated into the production of wheat straw crafts. The wheat straw crafts with distinct layers, reasonable perspective and rich luster and texture have triggered a major technological innovation and appearance change of wheat straw crafts. With the technological innovation and the rich means of production, the performance subject, content and form of wheat straw technology are more diverse, and scroll craft painting, wheat straw craft porcelain vases, screens and other forms of technology begin to appear. All kinds of wheat grass handicrafts expressing flowers, flowers and birds, characters, scenery, utensils, and folk patterns with hanging, vertical, seated as a carrier is perfectly combined with modern home, widely used in families, hotels, shops, conference halls and other private and public space.

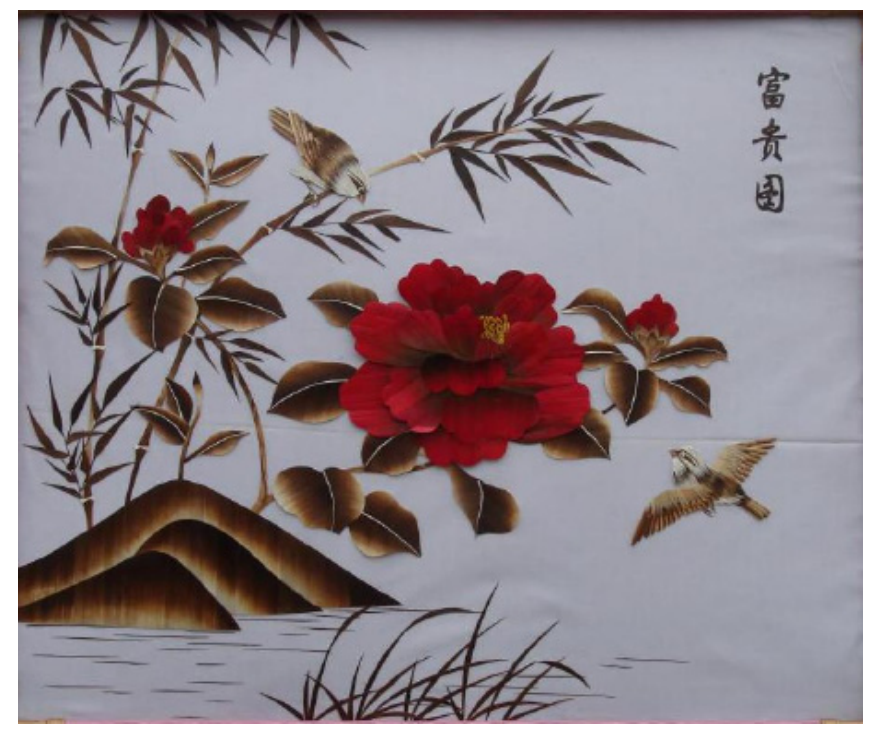

Figure. 3 Three-dimensional ironing wheat straw handicraft

\subsection{Renewal of Wheat Straw Process Tools to Promote the Redevelopment of Technology}

The tools used in the production of wheat straw technology are relatively simple. At first, there are only tools such as haircutter, scissors, carving knife, tweezers, and paper cutter. Later, the use of modern tools such as electric iron and electric soldering iron greatly enriched the expressive force of wheat straw technology.

Among the commonly used tools, the cutter is a special tool for breaking and grinding the wheat straw; sandpaper is mainly used to process the inner poles and stalk segments of the wheat straw to make the straw bright and flexible as paper; electric iron and electric collateral are tools for ironing the wheat straw, in which the electric iron is responsible for the overall picture processing. In general, different techniques such as drawing, painting, rubbing and dotting are used to make the wheat straw pictures with good shapes present a certain color level, forming the overall prototype of the picture. The temperature of electric irons in the process of ironing is 100-110 DEG C, which can be divided into high, medium and low color levels according to the different needs of the picture, but it takes ensuring the overall color, level and shape natural and soft as the standard; the electric collateral is mainly responsible for the description of the details of the picture. According to the needs of the specific design scheme, in the drawing, it makes a targeted coloring treatment. 


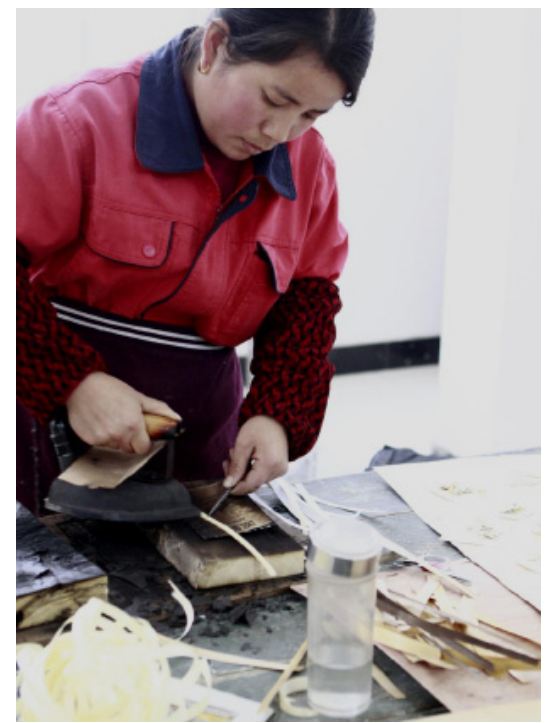

Figure. 4 Electric iron ironing

\subsection{Standardization of Technological Process to Promote the Redevelopment of Wheat Straw Technology}

The production process of Pucheng wheat straw is very complicated. From the choice of materials to the completion of products, there are the following main steps:

1. Handle wheat straw. In the process of treatment, Chinese herbal medicine should be used to soak it in order to achieve the anticorrosion effect, and then sulfur fumigation bleaching is used to increase the toughness of wheat straw and facilitate stripping and thinning.

2. Break the straw and grind the wheat straw. It can be divided into two knives, three knives, seven knives, nine knives and so on. The straw should be broken uniform and stubbleless. After that, 200 mesh sandpaper is used to remove the inner pulp of wheat straw, and the pulp is smoothly sanded so as to scrape the inner pulp, remove the outer knot and take out the dermis.

3. Drawing collage. According to the designed pattern, the broken and polished straw is patched into pieces to accurately express the shape of the image. In the specific collage process, it should be smooth and seamless, "horizontal, vertical, oblique, and rotational" different pasting methods should be flexibly used, so that the texture of wheat straw texture is consistent with pattern texture. For instance, it should be in line with the fiber tissues of plants or direction of animal feathers, to enhance the three-dimensional sense of the screen, light, texture and other performance effects.

4. Iron and dye. The pasted pictures are hot-pressed with electric soldering iron. Different colors are branded and basic figures are drawn by using different techniques such as scratching, painting, rubbing and dotting.

5. Cut and paste. According to the requirements of the design drawings, the different colored parts are cut off, and then the decomposed parts of the back of the picture are evenly glued and carefully pasted with tweezers according to the design drawings.

6. Combined iron and low temperature finish. The final fine-tuning is conducted on the whole pasted image with electric soldering iron to ensure the perfection of the picture, and then whole lowtemperature ironing drying and levelling is carried out with electric iron, which reveals the natural color of wheat straw and the characteristics of mosaic, relief and three-dimensional feeling.

7. Upper board and binding. Paste the finished work on the panel or canvas, supplemented by necessary board decoration, that is, pictures, subtitles, or flowers and watermarks, and add title and seal; then bind according to the picture image configuration frame. 


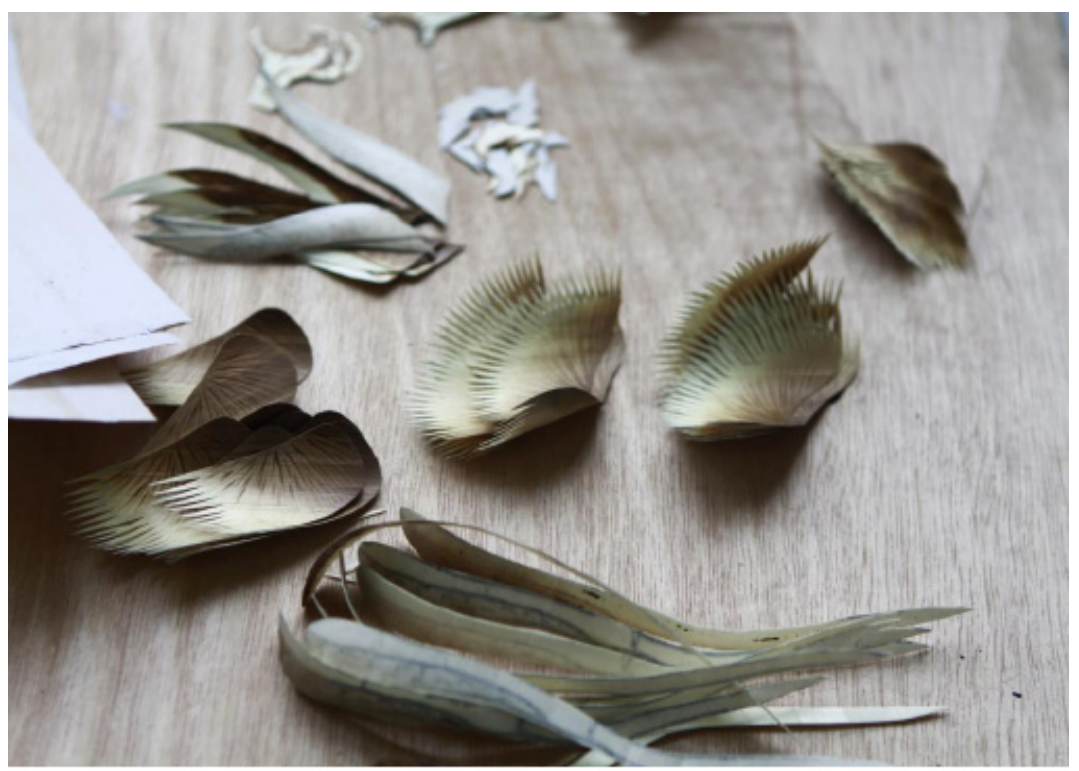

Figure. 5 Decomposition of wheat straw pictures

\section{Conclusion}

In China, where farming civilization has developed for thousands of years, there are many nationalities. The rich and colorful traditional national culture and folk art left by the ancestors of all nationalities should have become a rich spiritual food. However, in the process of industrialization and modernization with rapid economic development, many of them have inherited thousands of years of excellence are gradually declining. Under the premise that the state pays attention to the cultural development of "soft power", and under the background of vigorously promoting the protection of "intangible cultural heritage protection", the traditional handicraft industry just takes this good opportunity to embark on a new way of redevelopment.

\section{Acknowledgments}

Study of a Mechanisin for protection and Inheritance of Traditional Handicraft and Precise Proventy Alleviation in Poor Areas of Shanxi Province, a Social Science Fund Project in Shanxi Province in 2017, NO: 2017G004. Study of the Codeveloping Between Devitalization of Tradrtional Handicraft and Precise Poventy Alleviation in Poor Areas of Shanxi Province, an Important Theory and Practice Research Project in Social Science in Shanxi Province in 2018.NO.2018Z067. Moden Design for Revitalization of Tradional Handicraft in Old and Poor Area-- Take Jinding town, zhi Dan County for example, An Innovation and Startup Training Program for College Students in Shanxi Province in 2018.NO:201839004.

\section{References}

[1]. Farsani N T, Mortazavi M, Bahrami A, et al. Traditional Crafts: a Tool for Geo-education in Geotourism[J]. Geoheritage, 2017, 9(4):1-8.

[2]. Autio O. Traditional Craft or Technology Education: Development of Students' Technical Abilities in Finnish Comprehensive School.[J]. International Journal of Research in Education \& Science, 2016, 2(1):75.

[3]. Zofija Jankauskienè. Evaluation of the old Lithuanian flax cultivars included in the list of Lithuanian Traditional Crafts[J]. Zemdirbyste, 2018, 105(1):27-32. 
[4]. Yang Y, Shafi M, Song X, et al. Preservation of Cultural Heritage Embodied in Traditional Crafts in the Developing Countries. A Case Study of Pakistani Handicraft Industry[J]. Sustainability, 2018, 10(5):1336.

[5]. Affinito L, Conti G M, Motta M. New vision on Knitwear design. How the traditional craft methodologies are evolving into fashion international scenarios.[J]. Design Journal, 2017, 20(sup1):S2760-S2770.

[6]. Kimura Y. The Present Conditions and the Future of Traditional Crafts in Japan[J]. Hyomen Kagaku, 2017, 38(1):42-43. 